\title{
ANÁLISE DE INTERVENÇÃO INTERDISCIPLINAR NO 1․ ANO DO ENSINO MÉDIO DA ESCOLA ESTADUAL PIRASSUNUNGA, SP
}

\author{
PEDROSO-DE -MORAES, Cristiano ${ }^{1}$ \\ SILVA, Cássio Picinato Gomes da ${ }^{2}$ \\ FERREIRA, Lyard Libório ${ }^{3}$ \\ BERNARDO, Zilda Maria ${ }^{4}$ \\ SINOTTI, Ana Paula Siqueira Guimarães ${ }^{5}$
}

\begin{abstract}
RESUMO: O processo educativo possibilita formar pessoas com competência para participar de debates em escala mundial e em sociedades locais. A interdisciplinaridade, na formação do cidadão, rompe barreiras entre as disciplinas, sem desconsiderá-las, propondo uma integração curricular com o objetivo de construir um conhecimento globalizante. $\mathrm{O}$ objetivo deste trabalho foi avaliar a implantação de um projeto interdisciplinar focando conteúdos de ecologia vegetal, da disciplina de Biologia, obtidos por meio da tradução de artigos científicos e, posteriormente discutidos e apresentados tanto pelo ponto de vista biológico quanto filosófico pelos discentes partícipes do projeto. Cinco artigos científicos foram selecionados. Posteriormente, estes foram expostos aos professores de Língua Inglesa e Filosofia para concordância quanto à utilização em relação aos pressupostos presentes na Proposta Curricular do Estado de São Paulo. Realizou-se uma pesquisa quali-quantitativa participativa como procedimento metodológico com questionário estruturado. Para as disciplinas Biologia e Filosofia, a aplicação da interdisciplinaridade foi bastante positiva, enquanto que para a Língua Inglesa, obteve-se resultado moderado para a prática. A avaliação discente em relação à aplicação do projeto interdisciplinar evidenciou ampla aceitação e receptividade demonstradas pelas elevadas porcentagens obtidas nos quesitos positivos de avaliação relacionados à aprendizagem de conteúdos sobre desenvolvimento sustentável, preservação ambiental e à formação de um indivíduo ético, capaz de opinar e atuar sobre tais assuntos.
\end{abstract}

Palavras-chave: Interdisciplinaridade. Práxis pedagógica. Projetos educacionais

SUMMARY: (Analysis of an interdisciplinary intervention on $1^{\circ}$. grade of E. E. Pirassununga High School, SP.) the educational process makes it possible to train people with skills to participate in discussions on a global scale and in local societies. The interdisciplinarity in the training of citizens breaks down barriers between disciplines, without disregard them, proposing a curricular integration in order to build a globalizing knowledge. The objective of this study was to evaluate the implementation of an interdisciplinary project focusing on plant ecology contents in Biology, obtained through the translation of scientific articles and subsequently discussed and presented both the biological point of view as sociological by students of project. Five articles were selected. Later, they were exposed to English language and Philosophy teachers for agreement on the use regarding the present assumptions on the Curriculum Proposal of São Paulo State. We conducted a participatory qualitative and quantitative research as a methodological procedure with structured questionnaire. For the disciplines Biology and Philosophy the application of interdisciplinarity was quite positive, while for the English Language was obtained moderate result for the practice. The students' assessment regarding the application of the interdisciplinary project showed wide acceptance and responsiveness demonstrated by the high percentages obtained in the categories of assessment related to learning content on sustainable development, environmental preservation and the formation of an ethical individual, able to think and to act on such matters.

Keywords: Interdisciplinary. Pedagogical practice. Educational projects

\footnotetext{
${ }^{1}$ Prof. de Botânica Uniararas - Prof. PEB II de Biologia da SEE/SP. Uniararas

${ }^{2}$ Prof. PEB II de Lingua Inglesa. E.E.Pirassununga

${ }^{3}$ Prof. PEB II de Filosofia. E.E.Pirassununga

${ }^{4}$ Coordenadora do Ensino Fundamental da E. E. Pirassununga
} 


\section{INTRODUÇÃO}

De acordo com os Parâmetros Curriculares Nacionais (PCN) para o Ensino Médio (EM) (BRASIL, 1999), o Ministério da Educação, ao propor a reforma neste nível de ensino, procurou atender às necessidades das profundas mudanças sociais, econômicas, políticas, ambientais e culturais ocorrentes no mundo (MARTINS, 2000).

A adequação a tais necessidades advêm dos processos de globalização, devendo seguir as tendências reformistas ocorrentes em diferentes países em relação à educação, tema que vêm ocupando vários teóricos da área das ciências sociais, humanas e naturais (MARTINS, 2000).

Sob este aspecto, há consenso quanto ao impacto promovido pelas profundas mudanças econômicas, políticas, ambientais e culturais compreendidas no processo dinâmico da globalização, tanto no que diz respeito à análise acadêmica, quanto no que afeta ao discurso oficial (MARTINS, 2000, p 42). Dessa forma, integrações disciplinares geradas por intervenções educacionais multi e transdisciplinares apresentam-se como um dos caminhos para o desenvolvimento de habilidades e competências reais, baseadas em conteúdos realmente úteis e focadas na formação de indivíduos capazes de cumprir seus direitos e deveres constitucionais para com suas pátrias e, além de suas fronteiras, aptos a interagir em escala global no desenvolvimento das relações humanas, tecnológicas e de preservação ambiental (ORTIZ, 1998; BRASIL, 1999).

Nesse aspecto, processos educativos proveem educandos com conhecimentos e competências para que sejam capazes de participar de debates relacionados a temas globais e também, permitem que estes se tornem cidadãos cada vez mais participativos em suas relações sociais locais (SILVA; CARVALHO, 2002).

Neste sentido, para o Brasil, considera-se que: 1 - cabe ao ensino de Ciências da Natureza (Biologia, Física e Química), dotar os alunos de chaves essenciais para a solução de questões científicas e técnicas do cotidiano, principalmente em relação à interpretação de textos técnico-científicos (ASTOLFI; DEVELAY, 1998; SAVIANI, 2000; SILVA; CARVALHO, 2002; MENDONÇA et al., 2008); 2 - cabe às ciências humanas propiciar-lhes o desenvolvimento de atitudes e métodos de pensamento capazes de permitir relações de igualdade e respeito mútuas (Filosofia e Sociologia), bem como a capacidade de comunicação em nível global (Língua Inglesa) (BORGES et al., 2008; MARTINS; MICELI, 2008).

A incorporação dessas questões no currículo escolar proporciona contextos para a discussão de aspectos ambientais, sociais, econômicos, políticos, históricos, éticos e estéticos diretamente relacionados ao conhecimento humano e suas diversas aplicações (SILVA; CARVALHO, 2002). Entretanto, a existência de disciplinas no currículo escolar favorece a construção de um conhecimento fragmentário em relação à compreensão dos fenômenos naturais, sociais ou culturais (SENICIATO; CAVASSAN, 2004).

Sob tal aspecto, o princípio da interdisciplinaridade vem justamente romper barreiras entre as disciplinas, sem desconsiderá-las, ou seja, os objetos de estudo das disciplinas são mantidos e elas continuam a fazer parte do quadro curricular da escola. Assim, propõe-se uma integração curricular com o objetivo de construir um conhecimento globalizante, superando sua concepção fragmentária, sendo que, para isso, são constituídas equipes de docentes focados em planejar tais atividades integradoras de conhecimento (MORAES et al., 2015). Dessa forma, é proposta uma integração curricular com o objetivo de construir um conhecimento globalizante, superando sua concepção fragmentária (SANTOS, 2002).

A interdisciplinaridade constitui caminho para se alcançar a transdisciplinaridade, que, por sua vez, acaba com as fronteiras entre as disciplinas, propondo um trabalho que envolva exclusivamente projetos, capazes de gerar assimilações, habilidades e competências necessárias a real 
aprendizagem (MORAES et al., 2015).

Mediante o exposto, o presente trabalho teve por objetivo geral avaliar a implantação de um projeto interdisciplinar focando conteúdos de ecologia vegetal da disciplina de Biologia, obtidos por meio da tradução de artigos científicos em inglês e, discutidos e apresentados tanto pelo ponto de vista biológico quanto filosófico aos discentes do projeto. Especificamente, pretendeu-se verificar a eficácia da proposta para ensino-aprendizagem dos alunos, quanto à percepção em relação aos pontos positivos e negativos da metodologia aplicada e explicitar durante avaliações se tal práxis possibilita uma visão complexa dos fenômenos naturais por parte dos discentes, legitimando a importância do conhecimento da língua inglesa na obtenção de informações científicas seguras e discutindo os direitos e deveres da espécie humana quanto à alteração de ambientes naturais.

\section{MATERIAL E MÉTODO}

O projeto foi desenvolvido junto aos alunos da $1^{a}$. Série A do Ensino Médio da Escola Estadual Pirassununga, vinculada à Diretoria de Ensino de Pirassununga, SP., durante o $3^{\circ}$. Bimestre de 2014. O desenvolvimento do projeto ocorreu com a participação de 43 alunos e teve a duração de seis semanas, sendo relacionadas, portanto, duas semanas para casa disciplina envolvida.

Primeiramente, cinco artigos científicos de revistas internacionais e de ampla relevância científica, relacionados à degradação ambiental e perda/preservação de biodiversidade foram selecionados pelo professor de Biologia (MACDONNELL; PICKETT, 1990; MYERS et al., 2000; CHAPLIN III et al., 2000; CHMIELEWSKI; RÖTZER, 2001; PIMM et al., 2013) (Tabela 1), sendo que todos os conceitos abordados em tais trabalhos científicos estavam de acordo com a Proposta Curricular do Estado de São Paulo (MENDONÇA et al., 2008).

Tabela 1 - Títulos dos artigos selecionados para uso durante o trabalho interdisciplinar ministrado aos discentes da 1a. Série do Ensino Médio da Escola Estadual Pirassununga.

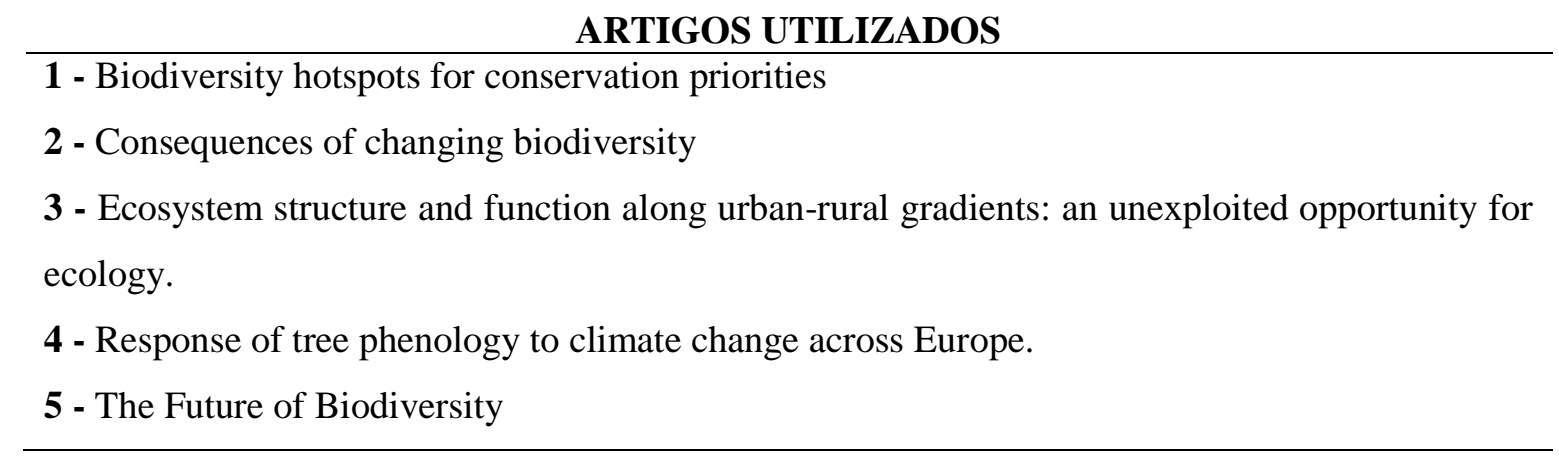

Posteriormente, estes foram expostos aos professores de Língua Inglesa e Filosofia para concordância, averiguação e correspondência quanto à utilização aos pressupostos e orientações presentes na Proposta Curricular do Estado de São Paulo para as respectivas disciplinas (BORGES et al., 2008; MARTINS; MICELI, 2008).

Este trabalho fundamentou-se em uma pesquisa quali-quantitativa participativa como procedimento metodológico, enquadrando-se aos propósitos iniciais da pesquisa para a consecução de seus objetivos (MORAES et al., 2015). Desta forma, foi utilizada a modalidade pesquisa-ação, por ser capaz de proporcionar a manifestação do coletivo (SILVA et al., 2014). 
Pode-se dizer que a pesquisa-ação é caracterizada como um tipo de pesquisa social com base empírica, concebida e realizada em estreita associação com uma ação ou com a resolução de um problema coletivo; a pesquisa não se limita à ação, pressupõe um aumento do conhecimento e do nível de consciência das pessoas ligadas à situação e do próprio pesquisador (THIOLLENT, 2000).

No intuito de avaliar a aprendizagem após a execução do projeto interdisciplinar, foi elaborado um questionário com questões objetivas e dissertativas, respondido pelos alunos uma semana após as intervenções, e corrigido coletivamente pelos professores componentes do projeto (SENICIATO; CAVASSAN, 2004; MORAES et al., 2015). Tal questionário foi subdividido em três partes: Parte I conteúdo apresentado nos artigos, para a verificação da aprendizagem de conteúdo especifico (Biologia utilizando questões objetivas e Inglês e Filosofia com questões objetivas/dissertativas). Parte II - aplicação e estrutura do projeto, para a avaliação por parte dos discentes (questões objetivas justificadas). Parte III Avaliação da interdisciplinaridade, por meio da avaliação da competência escritora (Quadro 1). Todos os resultados obtidos foram expressos em porcentagem e disponibilizados em gráficos. Quanto às respostas dissertativas e produção de texto, foram observados pelos docentes: coerência quanto ao tema e as regras de utilização da norma culta,

Quadro 1 - Questionário submetido aos alunos do primeiro ano do ensino médio após a realização do projeto interdisciplinar de Biologia-Inglês-Filosofia na E.E. Pirassununga. Pirassununga, SP.

\begin{tabular}{|c|}
\hline QUESTIONÁRIO INTERDISCIPLINAR \\
CONTEÚDO APRESENTADO NOS ARTIGOS \\
(PARTE 1) \\
Biologia
\end{tabular}

1) O conjunto de seres vivos ocorrentes em uma determinada unidade de área e que sofrem influencias bióticas e abióticas é denominado:

(A) Ecossistemas. (B) Fatores Abióticos. (C) Biodiversidade.

(D) Ecótono. (E) Bioma.

2) As principais áreas do planeta caracterizadas pela presença de elevada biodiversidade e com prioridade para a preservação são denominadas na atualidade de:

(A) Zonas de vida. (B) Biosfera. (C) Hotspots. (D) Bioma

(E) Macro-ecossistemas.

3) O mais biodiverso ecossistema brasileiro, que na atualidade corresponde a aproximadamente $6 \%$ da sua cobertura natural original é:

(A) A Mata Atlântica. (B) O Cerrado. (C) A Caatinga.

(D) A Floresta Amazônica. (E) A Mata dos Cocais.

4) $\mathrm{O}$ crescimento das grandes cidades, acarretou a degradação de grandes áreas e foi responsável por um dos principais processos capazes de afetar a biodiversidade. Assinale nas alternativas abaixo, qual
3) A inevitável devastação ambiental decorrente do processo de desenvolvimento industrial é um "quadro" que começa a se modificar a partir da defesa pública de um novo conceito: O DESENVOLVIMENTO SUSTENTÁVEL. O uso dessa expressão tem a finalidade de:

(A) sustentar a inevitável necessidade do desenvolvimento.

(B) garantir que o desenvolvimento contemporâneo não se sustenta.

(C) sustentar o meio ambiente em detrimento do desenvolvimento.

(D) propor a conciliação do desenvolvimento com o meio ambiente.

(E) divulgar a insustentável situação do meio ambiente.

4) Quais os interesses que movem as descobertas científicas e os avanços técnicos atuais?

5) Como a reflexão filosófica pode auxiliar a sociedade em sua relação com o meio ambiente? 
representa tal processo.

(A) Conurbação. (B) Fragmentação Florestal. (C) Especiação

(D) Pedogênese. (E) Gametogênese.

5) Atualmente estamos usando $25 \%$ mais recursos naturais do que o planeta é capaz de fornecer. O resultado é que espécies, habitats e comunidades locais estão sofrendo pressões ou ameaças diretas. A redução da biodiversidade significa que milhões de pessoas estão diante de um futuro em que:

(A) A água não será um fator limitante para a sobrevivência da espécie humana

(B) Os recursos genéticos mesmo que amplamente utilizados não desaparecerão

(C) A natureza irá se regenerar sem problemas futuros para a humanidade

(D) Estoques de alimentos serão mais vulneráveis a pragas e doenças e a oferta de água doce será irregular ou escassa.

(E) Estoques de alimentos serão mais abundantes, as pragas e doenças desaparecerão e a oferta de água doce será irregular ou escassa.

\section{Inglês}

1) According to your experience translating cientific articles, answer: what does "hotspot" mean?

(A) ambiente. (B) biodiversidade. (C) prioridade de preservação. (D) área devastada.

2) "Species-induced changes in microclimate can be just as important as the direct impacts of environmental change".

Read the sentence above and, then, choose the correct alternative of translation.

(A) As espécies ameaçadas de extinção aumentam a cada ano.

(B) As mudanças induzidas pelas espécies no microclima podem ser tão importantes quanto os impactos diretos da mudança ambiental.

(C) As alterações induzidas pelas espécies no macroclima são certamente mais importantes que os impactos diretos da mudança ambiental.

(D) Nenhuma das alternativas acima está correta.

3) Which of the following words are related to the study of the environment?

(A) Clock, watch, future, environment, ecosystem.

(B) Biodiversity, hotspots, extinction, love, science.

(C) future, science, ecosystem, fire, music.

(D) forest, species, hotspots, environment, ecosystem.

4) Read the sentence below and translate it into portuguese.

\section{APLICAÇÃO E ESTRUTURA DO PROJETO (PARTEII)}

\section{Avaliação discente}

1) O projeto proporcionou aumento de conhecimentos sobre a biodiversidade e a relação atual do homem com a natureza?

(A) $\mathrm{Sim}$

(B) Não

(C) Não sei responder

Justifique:

2) Na sua opinião, trabalhos interdisciplinares como o realizado, são importantes para a sua formação ?

(A) $\mathrm{Sim}$

(B) Não

(C) Não sei responder

Justifique:

3) O projeto realizado the proporcionou uma visão ampla da necessidade da preservação ambiental e da biodiversidade?

(A) $\mathrm{Sim}$

(B) Não

(C) Não sei responder

Justifique:

4) O desenvolvimento do projeto mediante trabalho em grupo proporcionou melhor aproveitamento $\mathrm{e}$ integração entre você e seus colegas?

(A) $\operatorname{Sim}$

(B) Não

(C) Não sei responder

Justifique:

5) O uso de artigos em língua inglesa lhe proporcionou a verificação e o entendimento de como a informação científica é propagada mundialmente e a importância 
"From an ecologist's perspective, urbanization desse idioma na divulgação de informações científicas? produces a variety of unprecedented and intense 'experimental manipulations"'.
(A) $\mathrm{Sim}$
(B) Não
(C) Não sei responder
Justifique:

5) Now, answer the question: in your opinion, what is the most precious good of humanity?

\begin{tabular}{|l}
\hline \\
\hline \\
\hline \\
\hline \\
\hline
\end{tabular}

\section{Filosofia}

1) Descreva como era a relação do homem na Grécia antiga (mitologia) com a natureza.

2) Observe a charge abaixo para responder a questão.

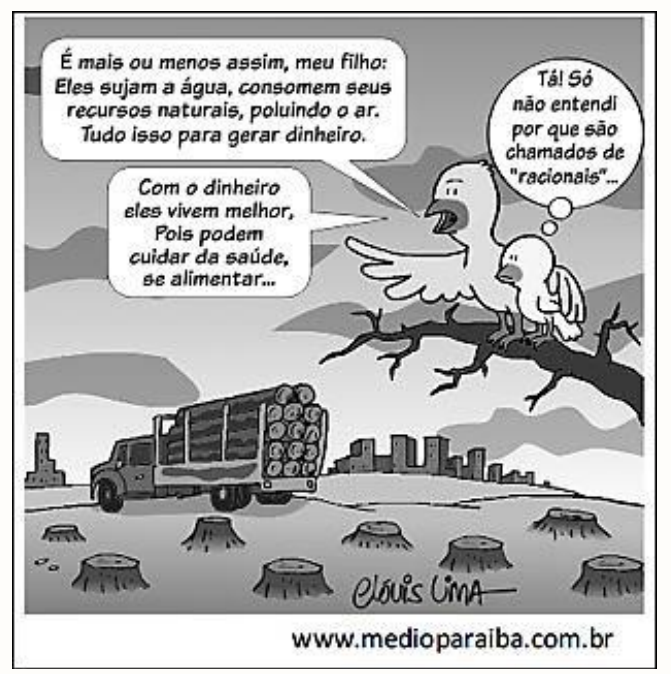

Ao questionar a racionalidade humana, a charge tem por objetivo principal:

(A) Relacionar o desmatamento à extinção das aves;

(B) Mostrar que os interesses econômicos sobrepõem-se à preservação ambiental;

(C) Mostrar que o uso de veículos contribui para o aumento da poluição atmosférica;

(D) Relacionar a expansão agrícola ao processo de degradação ambiental.

\section{AVALIAÇÃO DA INTERDISCIPLINARIEDADE (PARTE III)}

\section{Uso da competência escritora}

Questão Dissertativa - Escreva um mini texto descrevendo a importância na escola de se realizar trabalhos interdisciplinares (envolvendo diferentes disciplinas) principalmente, levando em consideração o projeto realizado com os artigos relacionados à biodiversidade.

\begin{tabular}{|l}
\hline \\
\hline \\
\hline \\
\hline \\
\hline \\
\hline \\
\hline \\
\hline \\
\hline \\
\hline \\
\hline
\end{tabular}




\section{RESULTADOS E DISCUSSÃO}

A análise dos resultados aponta que, para a disciplina de Biologia, a aplicação da interdisciplinaridade foi bastante positiva, pois, para todas as questões ministradas os acertos foram, no mínimo, da ordem de $70 \%$ (questão 1) e, no máximo, de $84 \%$ (questão 2) (Figura 1).

Figura 1 - Porcentagem dos acertos e erros das questões objetivas ministradas aos discentes da $1^{\text {a }}$. Série A do Ensino Médio da Escola Estadual Pirassununga, SP, para a disciplina de Biologia durante o desenvolvimento do trabalho interdisciplinar, no segundo semestre do ano de 2014.

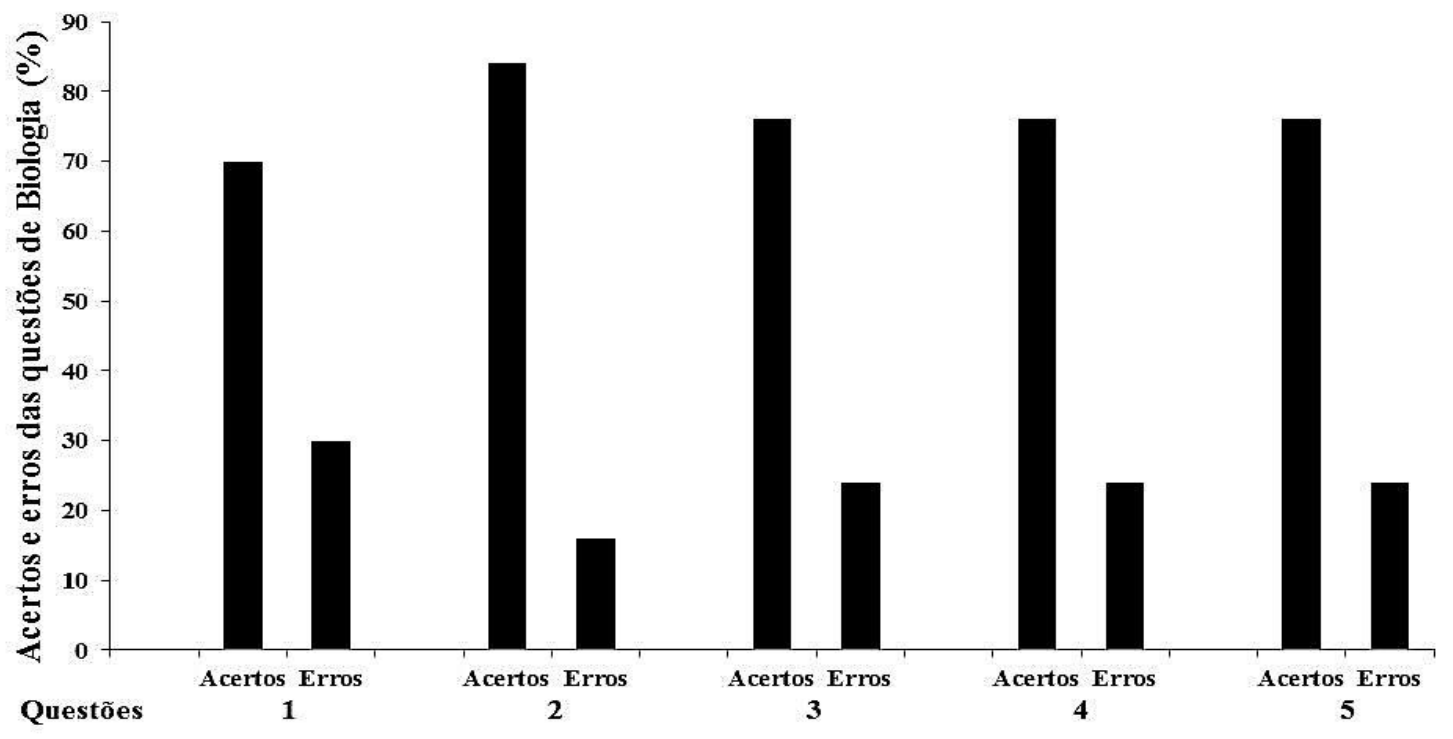

São escassos na literatura artigos abordando a aplicação prática direta da interdisciplinaridade com relação à Biologia, sendo a maioria dos trabalhos relegados à conceituação teórica (AUGUSTO et al., 2004), ou entrevistas realizadas com docentes e discentes (AUGUSTO; CALDEIRA, 2007) a respeito da aplicação de tal práxis para esta área do conhecimento dentro das Ciências da Natureza. Entretanto, como exemplo clássico relacionado à interdisciplinaridade em Biologia, evidencia-se nos anos 50 a "origem" da Biologia Molecular, ferramenta amplamente utilizada na atualidade e que é oriunda da união de físicos, químicos e biólogos (AUGUSTO et al., 2004).

Neste contexto, tal prática pedagógica deve ser redimensionada quando se leva em consideração a teoria acadêmica (MORIN, 2002a), uma vez que existe a necessidade premente desta ser construída na práxis cotidiana, pois, "no sentido do Em Tese, a interdisciplinaridade é entendida como a necessidade de integrar, articular e trabalhar em conjunto" (SEVERINO, 2001, p. 41). Sob tal ótica, professores de Biologia devem ser os responsáveis pela implantação da prática interdisciplinar nas unidades de ensino (UEs), sendo que "a reforma deve se originar dos próprios educadores e não do exterior" (MORIN, 2002b, p.35).

Analisando-se os resultados obtidos no presente trabalho com relação às questões respondidas pelos discentes, nota-se que o tema e o método empregado para integralização das disciplinas foi bastante satisfatório devido aos elevados acertos obtidos pelos alunos nas questões objetivas formuladas. Tal fato é corroborado por resultados semelhantes encontrados para trabalho interdisciplinar realizado por professores de Ciências da Natureza (Biologia, Física e Química) na cidade de Bauru, SP., nos quais o envolvimento entre as diferentes áreas do conhecimento foi mister para o desenvolvimento do trabalho sobre o "Conceito de Energia", sendo tal constatação, consenso entre os docentes e discentes 
entrevistados, pois estes, ...mencionaram este aspecto por ser um dos pilares mais claros e importantes que formam o conceito de interdisciplinaridade (AUGUSTO et al., 2004, p. 285). Ainda neste contexto, ressalta-se também, a importância do tema norteador de trabalhos interdisciplinares a serem implantados. Este, como no caso deste trabalho desenvolvido (Interpretação de artigos na língua inglesa sobre biodiversidade e entendimento de ações socioambientais), dever ser amplo e servir como um fácil e versátil unificador de disciplinas, pois, tal tema deve ser cotidianamente importante para as áreas envolvidas e apresentar a possibilidade de continuidade (AUGUSTO et al., 2004).

Docentes de Ciências da Natureza, de diferentes níveis de ensino, geralmente encontram dificuldades na implantação e desenvolvimento de trabalhos interdisciplinares. Tal dificuldade é devida a terem recebido formações fragmentárias do conhecimento científico (KLEIMAN; MORAES, 2002), isso faz com que o professor se sinta inseguro de dar conta da nova tarefa. Ele não consegue pensar interdisciplinarmente porque toda a sua aprendizagem realizou-se dentro de um currículo compartimentado (KLEIMAN; MORAES, 2002, p. 26). Contudo, conectar, relacionar e contextualizar conhecimentos constitui uma necessidade intrínseca do aprendizado humano, principalmente com influência cada vez maior da tecnologia e da informática nas salas de aula (AUGUSTO; CALDEIRA, 2007). Portanto, existe a necessidade tanto de capacitar professores para tal tipo de intervenção pedagógica, quanto de realizar o entrelaçamento das diferentes disciplinas a fim de se formar uma rede facilitadora da aprendizagem (MACHADO, 2000).

Com relação à interdisciplinaridade utilizada como pré-requisitos para ingresso em universidades brasileiras, análises realizadas em 2009, em relação aos conhecimentos biológicos necessário para a resolução das questões da Prova azul de Ciências da Natureza e suas Tecnologias do ENEM, evidenciaram que a contextualização das questões ocorreu em Ecologia (Conservação e Biodiversidade), Genética e Fisiologia, sempre ressaltando o conhecimento centífico presente no cotidiano físico do aluno. A interdisciplinaridade ocorreu pela união de conceitos de Biologia e Geografia, sendo que, neste contexto, pode ser verificada uma correlação profunda entre os conteúdos (MIRANDA, et al., 2010). Tal constatação vem ao encontro ao fato de que a contextualização multidisciplinar relacionada à temática ambiental, ocorrente dentro da disciplina de Biologia, é a mais utilizada devido ao seu grau de importância cotidiana, podendo ser destacado que:

A vida cotidiana e seus problemas ambientais são altamente complexos porque não se trata apenas de um número de diferentes elementos; trata-se também das interações entre tais elementos. Em uma visão simplista inicial, desenvolvimento histórico das ciências e das artes pode ser compreendido como uma diferenciação de certos problemas exteriores ao próprio processo dinâmico da vida cotidiana. Desse modo, atividades específicas desenvolvidas pelas artes, pelas ciências e pela tecnologia são empregadas para resolvêlas de maneiras pontuada. Por outro lado, deve haver também uma integração dos resultados dessas atividades no contexto da vida cotidiana (WALGENBACH et al., 2000, p.211-212).

Nesta ótica, percebe-se a necessidade da realização de pesquisas disciplinares especializadas (que significa disciplinaridade na interdisciplinaridade, o papel real de cada disciplina dentro da ação pedagógica conjunta) (KLEIN, 1990). Assim, temáticas relacionadas a problemas ambientais devem ser pautadas no conhecimento disciplinar e na expansão de ações integradoras para a criação de um novo conhecimento complexo (WALGENBACH et al., 2000, p. 227). Portanto, existe a necessidade de uma abordagem interdisciplinar que se baseie em uma situação complexa concreta, ou seja, a que determina o objeto de estudo da interação interdisciplinar (KLEIN, 1990), o que foi obtido neste trabalho pela utilização de artigos publicados em revistas científicas de ampla divulgação e relevância internacional. 
Para a disciplina de Inglês, a aplicação da interdisciplinaridade apresentou resultados satisfatórios apenas para as questões 1,3 e 5 e abaixo do esperado para as demais, sendo que o pior resultado foi o observado para a questão 2, com $80 \%$ de erro (Figura 2).

Figura 2 - Porcentagem dos acertos e erros das questões objetivas ou dissertativas ministradas aos discentes da 1 $1^{\text {a }}$. Série A do Ensino Médio da Escola Estadual Pirassununga, SP, para a disciplina de Inglês durante o desenvolvimento do trabalho interdisciplinar, no segundo semestre do ano de 2014.

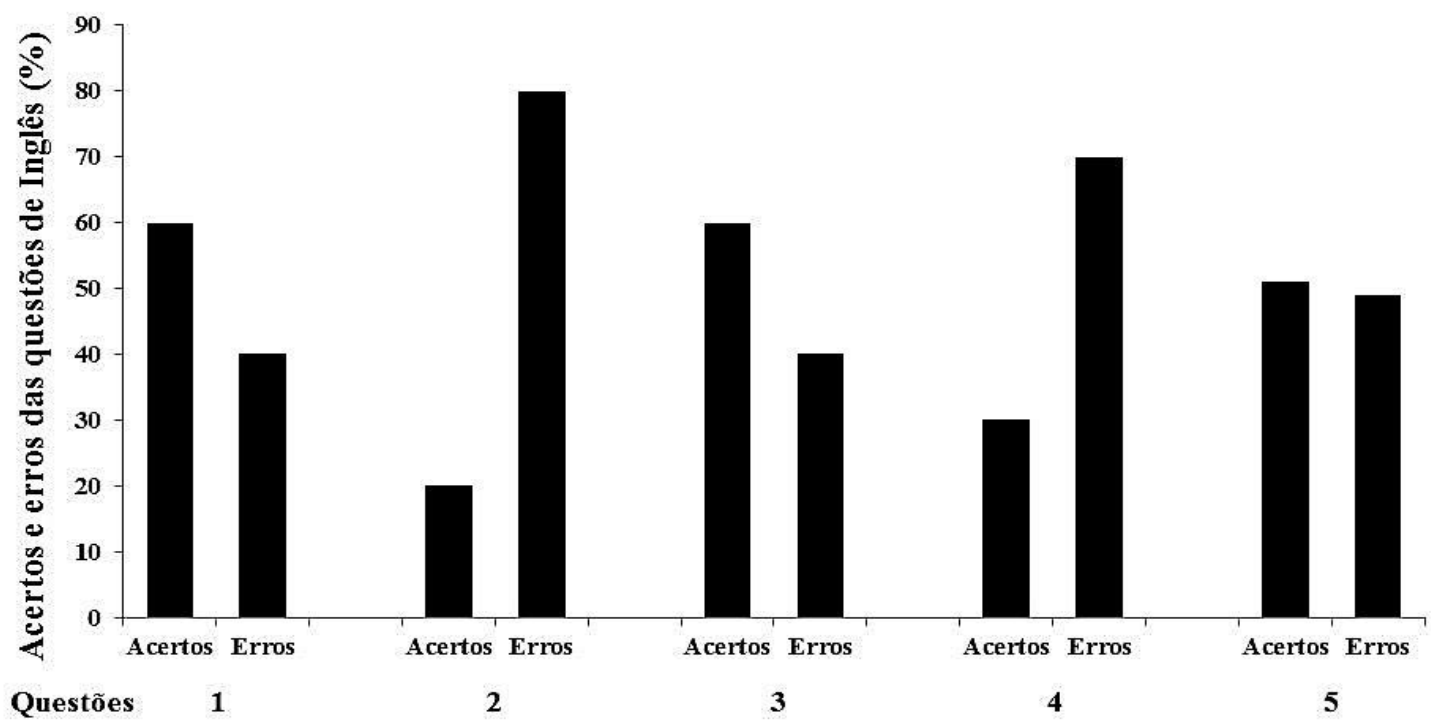

Historicamente, a LDB de 1996, juntamente com a mudança da nomenclatura dos ciclos de $1^{\circ}$ e $2^{\circ}$ graus, para Ensino Fundamental e Médio, explicitou a necessidade de uma Língua Estrangeira, ficando a escolha a cargo da comunidade escolar (BRASIL, 1996).

Sabe-se que existem várias dificuldades para a implantação e sistematização da Língua Inglesa nas UEs Médio brasileiras, contudo, tal disciplina deve ser contemplada e trabalhada em sala de aula, pois demonstra ampla importância na formação do aluno, principalmente com relação ao entendimento e interpretação de informações não disponíveis em nossa língua pátria e, também, quanto à necessidade de instrumentalização para o mercado de trabalho. Assim, a escola deve articular ações e projetos que permitam a interdisciplinaridade entre a Língua Inglesa e outras disciplinas elou oficinas, oferecendo ao educando uma aprendizagem significativa (MENDONÇA et al., 2011, p. 201).

Dessa forma, salienta-se que:

Se o ensino de uma língua estrangeira é dever da escola, e se grande parte das escolas oferece exclusivamente o inglês, e ainda se, no caso dos alunos das camadas populares, a escola pública é o único lugar de aprendizado desse idioma, é de se esperar que seu ensino seja eficaz e significativo para eles, possibilitando-lhes o acesso ao direito de formação integral do indivíduo a fim de que possam exercer a tão proclamada "cidadania" e utilizar o conhecimento adquirido como mecanismo de inclusão social (BERNARDO, 2007, p. 95).

Contudo, muitos são os problemas relacionados ao ensino de tal língua estrangeira nas escolas brasileiras. A literatura específica para professores de Língua Inglesa apontam como as principais causas da ineficiência do ensino e aprendizagem, os seguintes fatores: 1 (des)motivação; $\mathbf{2}$ classes numerosas e $\mathbf{3}$ utilização de metodologias inadequadas (MACAU, 2006; BARBARDO, 2007; MENDONÇA et al., 2011). 
Com relação à proposta metodológica empregada nesse trabalho, observa-se que a utilização de artigos relacionados à temática ambiental publicados em Língua Inglesa e traduzidos pelos alunos com o auxílio do docente é bastante relevante, pois vem ao encontro à importância que tal língua tem ocupado na história da humanidade, ou seja, um papel de destaque no cenário mundial. Idioma da divulgação do conhecimento científico, da internet e língua franca das instituições internacionais, sua difusão tem alcançado proporções inigualáveis na história das línguas (BERNARDO, 2007, p.95).

Dessa forma, atribui-se para este trabalho, como um dos fatores responsáveis para a maior porcentagem de erro obtida pelos discentes para as questões 2 e 4 (Figura 2) da Parte 1 - conteúdo de Inglês (Quadro 1), do questionário aplicado após a intervenção traducional realizada, a desmotivação, gerada pelo número de alunos por classe, atrelada à metodologia empregada no desenvolvimento da intervenção, pois os conhecimentos e competências prévios e pré-requisitos necessários das disciplinas integrantes do projeto foram atestados pelos professores do $9^{\circ}$. ano antes da realização da pesquisa.

Tal sugestão vem ao encontro dos bons resultados obtidos para as demais disciplinas envolvidas no trabalho e na análise positiva da intervenção interdisciplinar realizada por parte dos discentes (Figuras 1,3 e 4). Além disso, devido ao grande número de alunos por sala, houve a necessidade da formação de grupos de trabalho compostos por 6-7 integrantes, o que dificultou a integração dos discentes, os quais acabaram optando por "dividir o artigo" para terminar a tradução, enquanto, o correto e veementemente instruído pelo professor, era a realização conjunta do procedimento, uma vez que havia tempo hábil estabelecido para isso, corroborando o fato de que a desmotivação foi, em grande parte, gerada pelo número excessivo de discentes na sala.

Outra possível causa para a desmotivação e o baixo desempenho em algumas das questões do questionário aplicado esta atrelada ao fato de que os alunos de escolas públicas não utilizam muito o inglês no dia-a-dia, mas quando o fazem recorrem à música, internet e video games (BERNARDO, 2007, p.103). Possivelmente, uma leve alteração da metodologia, visando à composição de duplas para a tradução em salas de informática, poderia ser uma saída para o aprimoramento de trabalhos semelhantes ao aqui realizado.

As análises dos resultados revelaram que a maioria dos alunos gosta e considera importante o aprendizado da Língua Inglesa, assim como o também constatado em outros trabalhos (MENDONÇA et al., 2011), assim como o constatado para alunos do ensino fundamental de escola pública situada no município de Aracajú, SP., para os quais a escola,

..é vista como o lugar de aprendizagem desse idioma, diferentemente do que qualquer análise apressada poderia supor. Essa crença na função da escola regular como lugar legítimo do aprendizado da língua estrangeira é um fator importante e estimulador da busca de soluções para o enfrentamento dos problemas relativos a esse ensino (BERNARDO, 2007, p.104).

Salienta-se que o ensino da Língua Inglesa pode ser o fomentador de ações capazes de proporcionar uma grande amplitude de questionamentos, pois permite a apresentação de uma realidade não vivida, mas que, por ser essencial, deve ser inserida em nosso meio profissional (MENDONÇA et al., 2011).

Assim, como o ocorrido para a Biologia, para a disciplina de Filosofia, a aplicação da interdisciplinaridade foi positiva, pois, para todas as questões ministradas os acertos foram de no mínimo $52 \%$ (questão 3) e no máximo de 68\% (questão 2) (Figura 3). 
Figura 3 - Porcentagem dos acertos e erros das questões objetivas ministradas aos discentes da $1^{\text {a }}$. Série A do Ensino Médio da Escola Estadual Pirassununga, SP, para a disciplina de Filosofia durante o desenvolvimento do trabalho interdisciplinar no segundo semestre do ano de 2014.

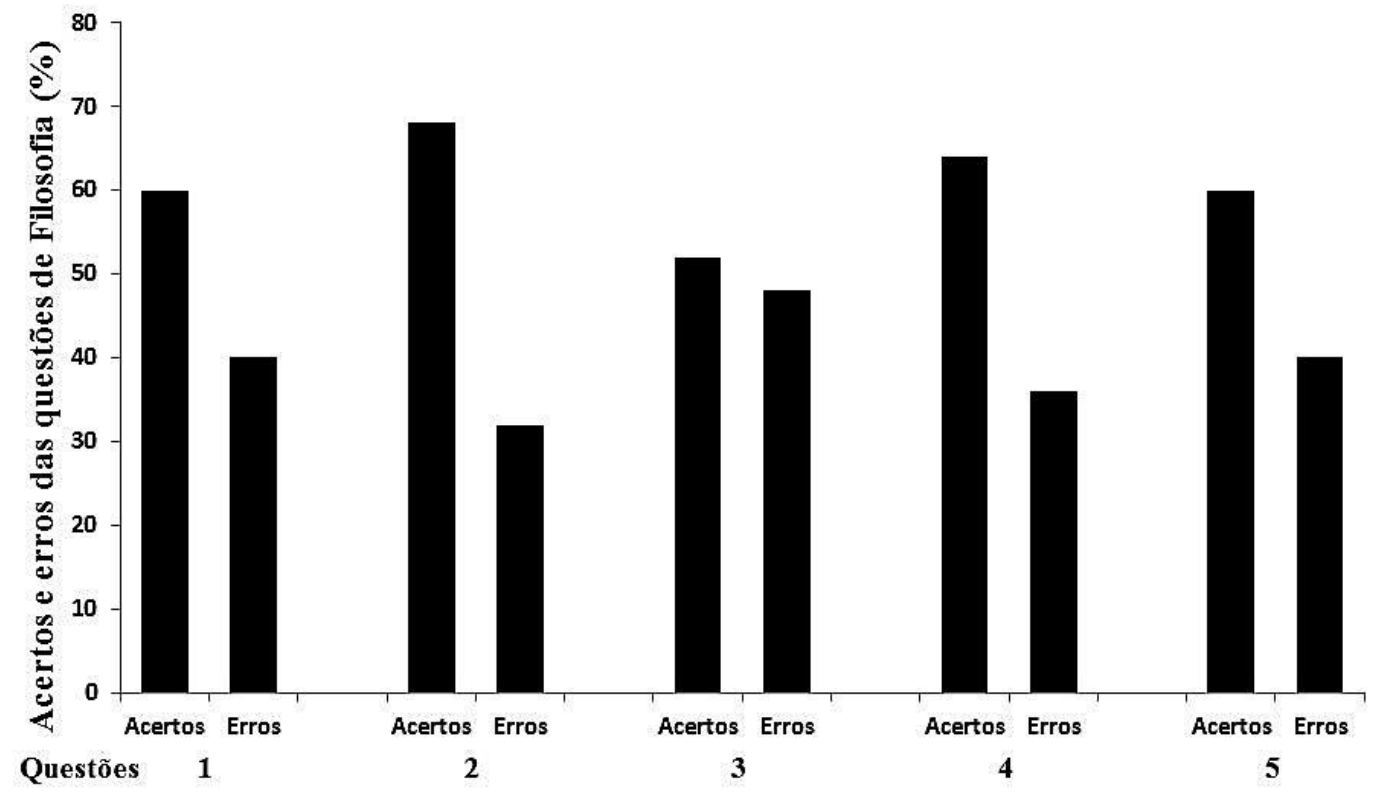

Para o ensino médio, a Lei de Diretrizes e Bases da Educação (BRASIL, 1999), preconiza que o estudante deve assimilar conhecimentos filosóficos que permitam o exercício da real cidadania. Contudo, não define como estes conteúdos devam ser ministrados (GALLO, 2004). Neste contexto, a formação que se deseja da escola, constitui um processo que deve permitir maior autonomia do educando, sendo tal processo uma tarefa conjunta de todo o currículo, ou seja, de responsabilidade de todas as disciplinas, com a Filosofia, neste aspecto, constituindo uma das principais ferramentas capazes de gerar a integração dos conteúdos das ciências, na busca de uma visão integrada do homem (SEVERINO, 1990), suscitando, no sujeito uma sensibilidade diretamente relacionada a significações de aspectos de sua existência, os quais as demais disciplinas do currículo escolar não têm condições de fornecer em decorrência de sua própria natureza e conteúdo (SEVERINO 2011).

A benéfica aplicação e as importantes características e peculiaridades supracitadas da Filosofia puderam ser observadas no bom desempenho obtido pelos alunos durante a intervenção interdisciplinar realizada (Figura 3) e pela ampla aceitação da realização do próprio trabalho por parte dos discentes (Figura 4 - Parte II).

Infelizmente, se para as demais disciplinas contextualizadas neste trabalho são poucas as informações oriundas de trabalhos práticos (intervenções em escolas) para a realização de discussão de resultados, para a disciplina de Filosofia, a obtenção de documentos passíveis de serem utilizados para comparação científica, com a intervenção aqui realizada, é ainda mais escassa, sendo encontrados principalmente, textos teóricos sobre sua aplicabilidade (SEVERINO, 1990; GALLO, 2004; SEVERINO 2011), demonstrando que tal disciplina ainda necessita de maior integralização com as demais, a fim de permitir um pleno desenvolvimento educacional do Educando, segundo uma práxis cotidiana real. A existência concreta de tal práxis permitirá que:

...a Filosofia se torne formativa, na medida em que ela permite ao jovem dar-se conta do lugar que ocupa na realidade histórica de seu mundo, como ele se situa no seu contexto real de existência. Cabe à Filosofia, pois, ajudá-lo a compreender o sentido de sua própria experiência existencial, situando-a em relação ao sentido da existência humana em geral. Pode-se então dizer que o papel pedagógico da Filosofia, na condição de uma 
mediação curricular, é o de subsidiar o jovem aprendiz a ler o seu mundo e a se ler inserido nele. Eis por que se diz que se quer levar o aluno à reflexão, ao exercício do pensamento, à apreensão do sentido das coisas. Isso nos põe diante do fato de que, com a inclusão de componentes filosóficos nos currículos, não se tem em mira a preparação de um especialista em Filosofia, no sentido acadêmico de se formar um filósofo técnico. E esse fato já exige uma inflexão na nossa prática de ensinar Filosofia, diferenciando a postura didática, quando se trata do trabalho docente num curso de graduação em Filosofia daquela que se impõe desenvolver em aulas de Filosofia em outros cursos de graduação e muito mais ainda em cursos de ensino básico (SEVERINO, 2011, p. 82).

No contexto da aplicação cotidiana da Filosofia para a formação de sujeitos educandos, evidenciase que, com relação à temática ambiental, a importância da disciplina como integradora de conhecimentos é corroborada pelas respostas dadas pelos discentes às perguntas dissertativas que compuseram a avaliação desta área do conhecimento neste trabalho, principalmente com relação à quinta questão (QUADRO 1, conteúdo de Filosofia), da qual apresentam-se algumas respostas abaixo:

A reflexão filosófica pode nos ajudar a termos mais consciência para um futuro melhor e que não acabe com toda a nossa biodiversidade e com nossos ecossistemas (Aluna no8).

Muitas pessoas realizam palestras e trabalhos voltados para a conscientização relacionados à ecologia e seus movimento e também alguns protestos que caracterizam tipos de reações que são vindas das reflexões e considerações filosóficas (Aluna no32).

Pode levar o homem a pensar se iremos ter um futuro. Somente com reflexões e discussões poderemos chegar a "acordos" e ações que permitam o desenvolvimento sustentado (Aluno nㅇ42).

Sermos mais racionais, já que se "penso, logo existo", isso poderia garantir a preservação ambiental, pois permite que discutamos as propostas de governantes quando à preservação das espécies animais e vegetais (Aluno no42).

Com relação à avaliação da interdisciplinaridade, observou-se por parte dos discentes, como anteriormente citado, ampla aceitação e receptividade em relação ao desenvolvimento de tal práxis. Tal constatação é corroborada pelas elevadas porcentagens obtidas para os resultados positivos, de no mínimo $68 \%$ para a questão 4 e de no máximo 92\% para a questão 3 (Figura 4), sendo portanto, tais dados, indicativos cabais do sucesso da aplicação da intervenção interdisciplinar (Quadro 1).

Esses resultados estão de acordo com o sugerido por diversos autores de que tal práxis melhora a aprendizagem, ao mesmo tempo em que estabelece práticas educacionais que motivam os discentes e os levam ao desenvolvimento da auto regulação da aprendizagem (VEIGA-NETO, 1994; ROSA, 2007; CARDOSO et al., 2008), pois, a prática do ensino interdisciplinar aproveita-se das conexões naturais e lógicas que cruzam as áreas de conteúdos e organiza-se ao redor de perguntas, temas, problemas ou projetos, em lugar de conteúdos restritos. Entretanto, elucubra-se que a não minimização da importância dos conteúdos é fundamental, pois o equilíbrio entre o disciplinar e o interdisciplinar é necessário, uma vez que as áreas específicas possuem um cabedal de conhecimento acumulado ao qual o aluno deverá também ter acesso (COSTA, 2008). Tais constatações realizadas, algumas vezes antitéticas, em relação a esta prática são corroboradas pela afirmação de que

...nos Parâmetros Curriculares Nacionais (PCN), a interdisciplinaridade se fundamenta na crítica de uma concepção que toma a realidade como um conjunto de dados estáveis e refere-se a uma abordagem epistemológica dos objetos de conhecimento questionando a segmentação entre os diferentes campos do saber produzida por uma visão compartimentada (disciplinar), que apenas informa sobre a realidade sobre a qual a 
escola, tal como é conhecida, historicamente se constituiu (KLEIMAN; MORAES,1999, p. 22).

Figura 4 - Porcentagens obtidas para as questões avaliativas respondidas pelos alunos da $1^{\text {a }}$. Série A do Ensino Médio da Escola Estadual Pirassununga, SP, após o desenvolvimento do trabalho interdisciplinar no segundo semestre do ano de 2014.

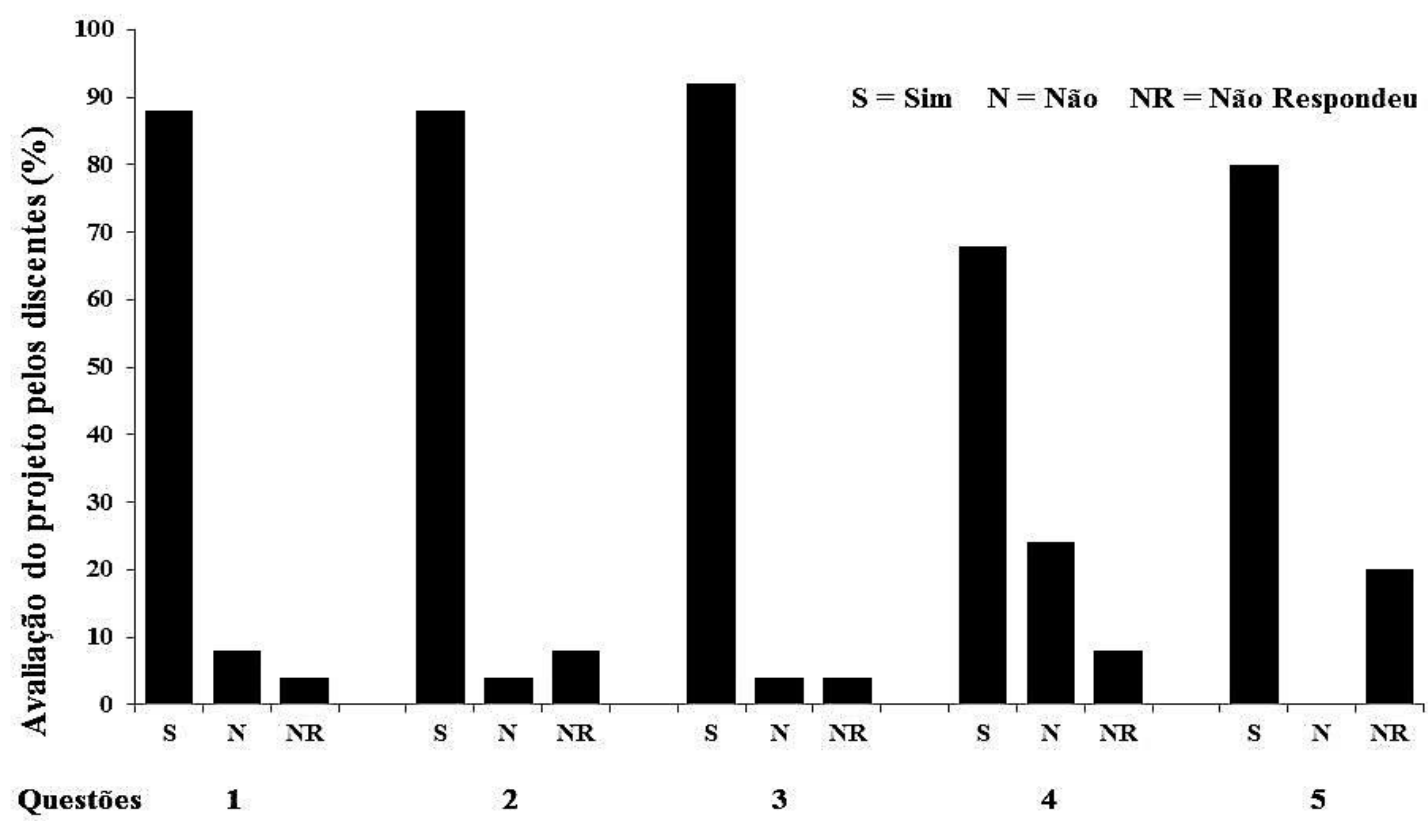

Quanto á coerência argumentativa e a utilização da norma culta por parte dos discentes na Parte III (Quadro I), a análise dos textos produzidos demonstram domínio satisfatório das competências leitora e, principalmente, escritora, pelos alunos envolvidos no projeto.

\section{CONCLUSÃO}

Para as disciplinas Biologia e Filosofia a aplicação da interdisciplinaridade foi bastante positiva, tendo-se verificado o aprendizado das temáticas relacionadas ao desenvolvimento sustentável, à preservação ambiental e à formação de um indivíduo ético, capaz de opinar e atuar sobre tais assuntos, o que é preconizado pelos Parâmetros Curriculares Nacionais.

Para a Língua Inglesa, obteve-se resultado moderado para a prática, fato este atribuído ao grande número de alunos por sala e pela necessidade de melhor adequação da metodologia empregada. Para este componente curricular, a proposta de temas interdisciplinares relacionadas a técnicas traducionais, seria mais efetiva, se ao invés de trabalhos em grupos, fossem formadas duplas por parte dos alunos, fosse utilizada a sala de informática para dinamizar este tipo de atividade e a presença de menor número de discentes por sala de aula.

A avaliação discente em relação à aplicação do projeto interdisciplinar evidenciou ampla aceitação e receptividade demonstradas pelas elevadas porcentagens obtidas nos quesitos de avaliação. O que abre perspectivas para uma maior aplicação de práticas, como a aqui explicitada. Contudo, devido à particularidade de cada componente curricular, faz-se necessário amplo planejamento integrado para a aplicação e desenvolvimento eficaz de projetos didáticos interdisciplinares e o amplo desenvolvimento de oficinais de formação, oferecidas pelo poder público, para os docentes interessados em realizar este tipo de intervenção pedagógica, visando melhorar e dinamizar a aprendizagem de seus alunos. 


\section{REFERÊNCIAS}

ASTOLFI, J. P.; DEVELAY, M. Didática das Ciências. Campinas: Ed. Papirus. 1995.

AUGUSTO, T. G. S. et al. Interdisciplinarity: conceptions of the teachers for the Natural Sciences Area in formation in service. Ciência \& Educação, v. 10, p. 277-289, 2004

AUGUSTO, T.G.S.; CALDEIRA, A. M. A. Dificuldades para a implantação de práticas interdisciplinares em Escolas Estaduais, apontadas por professores da área de Ciências da Natureza. Investigações em Ensino de Ciências, v.12, p. 139-154, 2007.

BERNARDO, A. C. Língua Inglesa na escola pública e a relação com o saber. Interdisciplinar, v. 4, p. 94-105, 2007.

BORGES, A. R. W. et al. Proposta Curricular do Estado de São Paulo: LEM - Inglês. São Paulo: Secretaria da Educação do Estado de São Paulo - SEE. 2008. 56p.

BRASIL. Parâmetros Curriculares Nacionais para o Ensino Médio: Parte I - Bases Legais. Brasília. 1999.

CHAPLIN III, F. S.; et al. Consequences of changing biodiversity. Nature, v. 405, p. 234-242, 2000.

CHMIELEWSKI, F. M.; RÖTZER, T. Response of tree phenology to climate change across Europe. Agricultural and Forest Meteorology, v. 108, p.101-112, 2001.

COSTA, A. Interdisciplinaridade e transversalidade: considerações sobre a epistemologia do trabalho escolar brasileiro. Cadernos de Linguagem e Sociedade, v.9, p.25-44, 2008.

GALLO, S. A função da filosofia na escola e seu caráter interdisciplinar. Revista Sul Americana de Filosofia e Educação, v. 2, p. 1-4, 2004.

KLEIMAN, A. B.; MORAES; S. E. Leitura e interdisciplinaridade: tecendo redes nos projetos da escola. Campinas: Mercado de Letras, 1999. 91p.

KLEIN, J. T. Interdisciplinarity: history, theory and practice. Detroit: Wayne State University Press; 1990. 172p.

MACAU, L. M. R. As apresentações dos professores de inglês do Ensino Médio, sobre os PCNs e a sua aplicabilidade. 2006, 105f. Dissertação (Mestrado em Linguística Aplicada e Estudos de Linguagem). Pontifícia Universidade Católica de São Paulo, SP.

MACDONNEL, M. J.; PICKETT, S. T. A. Ecosystem structure and function along urban-rural gradients: an unexploited opportunity for ecology. Ecology, v.71, p. 1232-1237, 1990.

MACHADO, N. J. Educação: projetos e valores. 3. ed. São Paulo: Escrituras, 2000. 136p.

MARTINS, A. L.; MICELI, P. Proposta Curricular do Estado de São Paulo: Filosofia. São Paulo: Secretaria da Educação do Estado de São Paulo - SEE. 2008. 48p.

MARTINS, A. M. Diretrizes curriculares nacionais para o ensino médio: avaliação de documento.

Cadernos de Pesquisa, v. 109, p. 67-87, 2000.

MENDONÇA, F. B. et al. Proposta Curricular do Estado de São Paulo: Biologia. São Paulo: Secretaria da Educação do Estado de São Paulo - SEE. 2008. 44p. 
MENDONÇA, M. P. C.; LOBATO, I. M.; PEREIRA, J. R. S. Interdisciplinaridade: um diálogo da língua inglesa moderna com a educação integral através de oficinas pedagógicas. Polyphonía, v. 22, p. 109-207, 2011.

MIRANDA, E. M. et al. ENEM 2009: articulações entre CTS, interdisciplinaridade e contextualização evidenciadas nas questões das Ciências da Natureza. Anais....II Seminário Ibero-Americano CiênciaTecnologia-Sociedade no Ensino das Ciências. Brasília - DF: Universidade de Brasília, 2010. Pp. 1-12.

MORAES, C. P. et al. Prática de campo: aprendizagem sobre biodiversidade e preservação ambiental verificada em discentes da Escola Estadual Pirassununga, SP. Nucleus, v.12, p. 361-369. 2015.

MORIN, E. A cabeça bem-feita: repensar a reforma, reformar o pensamento. 7. ed. Rio de Janeiro: Bertrand Brasil, 2002. 131p.

MORIN, E. Educação e complexidade: os sete saberes e outros ensaios. São Paulo: Cortez, 2002b. 114p.

MYERS, N.et al.. Biodiversity hotspots for conservation priorities. Nature, v. 403, p. 853-858, 2000.

ORTIZ, R. Mundialização, cultura e política. In: DOWBOR, L., IANNI, O., REZENDE, P. E. A. (org.). Desafios da globalização. Petrópolis: Vozes. 1998. Pp. 270-275.

PIMM, S. L.; et al. The Future of Biodiversity. Science, v. 269, p. 347-350, 2013.

SANTOS, S. A. M. A excursão como recurso didático no ensino de biologia e educação ambiental. In: ENCONTRO PERSPECTIVAS DO ENSINO DE BIOLOGIA, 6, 2002, São Paulo. Anais... São Paulo: FEUSP, 2002. 1 CD-ROM.

SAVIANI, N. Saber escolar, currículo e didática: problemas da unidade conteúdo/método no processo pedagógico. Campinas, SP: Autores Associados, 2003. 200 p.

SENICIATO, T.; CASSAVAN, O. Aulas de campo em ambientes naturais e aprendizagem em ciências um estudo com alunos do fundamental. Ciência \& Educação, v. 10, p. 133-147, 2004.

SEVERINO, A. J. A contribuição da Filosofia para a Educação. Em Aberto, v.9, p. 18-25, 1990.

SEVERINO, A. J. O conhecimento pedagógico e a interdisciplinaridade: o saber como intencionalização da prática. In: FAZENDA, I. C. A. (Org.). Didática e interdisciplinaridade. Campinas: Papirus, 2001. p. 41.

SEVERINO, A. J. Do ensino da filosofia: estratégias interdisciplinares. Educação em Revista, v.12, p.8196, 2011

SILVA, L. F.; CARVALHO, L. M. A Temática ambiental e o ensino de Física na escola média: algumas possibilidades de desenvolver o tema produção de energia elétrica em larga escala em uma situação de ensino. Revista Brasileira de Ensino Física, v. 24, p. 342-352, 2002.

SILVA, L. L. da; DINIZ, E. M.; PEDROSO-DE-MORAES, C. Análise da percepção ambiental de um grupo de alunos com necessidades educacionais especiais educacionais. Revista Científica da FHO|UNIARARAS, v. 2, p. 1-9, 2014.

THIOLLENT, M. Metodologia da pesquisa-ação. 10. ed. São Paulo: Autores Associados, 2000. 235p.

WALGENBACH, W.; MARTINS, R. P.; BARBOSA, F. A. R. Modos Operativos de Integração Disciplinar nas Ciências Ambientais. In: PHILIPPI Jr., A. (Coord.). Interdisciplinaridade em Ciências Ambientais. São Paulo: Signus Editora 
